This is the author's final, peer-reviewed manuscript as accepted for publication. The publisher-formatted version may be available through the publisher's web site or your institution's library.

\title{
Interdependence of structure and physical properties in co- crystals of azopyridines
}

Christer B. Aakeröy, Sheelu Panikkattu, Baillie DeHaven and John Desper

\section{How to cite this manuscript}

If you make reference to this version of the manuscript, use the following information:

Aakeröy, C. B., Panikkattu, S., DeHaven, B., \& Desper, J. (2013). Interdependence of structure and physical properties in co-crystals of azopyridines. Retrieved from http://krex.ksu.edu

\section{Published Version Information}

Citation: Aakeröy, C. B., Panikkattu, S., DeHaven, B., \& Desper, J. (2013). Interdependence of structure and physical properties in co-crystals of azopyridines. CrystEngComm, 15(3), 463-470.

Copyright: (c) The Royal Society of Chemistry 2013

Digital Object Identifier (DOI): doi:10.1039/c2ce26153g

Publisher's Link: http://pubs.rsc.org/en/content/articlelanding/2013/ce/c2ce26153g 


\title{
Interdependence of structure and physical properties in co-crystals of azopyridines
}

\author{
Christer B. Aakeröy, ${ }^{a *}$ Sheelu Panikkattu, ${ }^{a}$ Baillie DeHaven a and John Desper ${ }^{\mathrm{a}}$
}

\begin{abstract}
5 To establish how intermolecular interactions influence supramolecular assembly of azopyridines, a total of five co-crystals of 3,3' and 4,4'-azopyridine; 3,3'-azpy:succinic acid (3,3'-azpy:SA), 3,3'-azpy:adipic acid (3,3'-azpy:AA), 3,3'-azpy:suberic acid (3,3'-azpy:SuA), 3,3'-azpy:sebacic acid (3.3'-azpy:SeA), and 4,4'-azpy:suberic acid (4,4'-azpy:SuA) were synthesized. In all co-crystals of 3,3'-azopyridine, there are infinite 1-D zig-zag tapes composed of alternating 3,3'-azpy and diacids held together by $\mathrm{COOH} \cdots \mathrm{N}(\mathrm{py})$

10 hydrogen bonds. Neighbouring chains are arranged into 2-D sheets via secondary inter-chain C-H $\cdots \mathrm{O}$ interactions between azopyridine ring hydrogen atoms and carbonyl oxygen atoms in an in-phase manner. However, in the co-crystal of 4,4'-azopyridine:suberic acid, the adjacent chains form 2-D sheets in an out-of-phase motif via two types of inter-chain $\mathrm{C}-\mathrm{H} \cdots \mathrm{O}$ interactions, i.e. between azopyridine ring hydrogen atoms and carbonyl oxygen as well as hydroxyl oxygen atoms. The structural consistency 15 within the 3,3'-azopyridine co-crystals has made it possible to establish a correlation between melting point of the homomeric molecular solids and co-crystals of the corresponding carboxylic acids.
\end{abstract}

\section{Introduction}

20 The construction of molecular solids can be achieved via selective assembly processes driven by molecular recognition, ${ }^{1}$ and hydrogen bonding ${ }^{2}$, halogen bonding ${ }^{3}$ and $\Pi \cdots \Pi$ stacking $^{4}$ are examples of non-covalent interactions that can be used as 'supramolecular glue' to connect individual building blocks into a 25 3-D network.

Co-crystals ${ }^{5}$ have attracted considerable attention due to their wide range of applications in areas of functional solids such as pharmaceutics $^{6}$ and energetic materials. ${ }^{7}$ Hydrogen bonds have become the interaction of choice when preparing co-crystals 30 thanks to advances in predicting which synthons will form given the presence of certain chemical functionalities. ${ }^{8}$ However, apart from knowledge of interactions that drive the initial supramolecular assembly, better insight into the weaker forces that subsequently connect these architectures is important for 35 consistent structure prediction. An important aspect of crystal engineering is the deliberate synthesis of new solid forms with pre-determined connectivity and topology as this will offer a path towards the design of materials with pre-determined bulk properties. With the help of reliable control of the inter40 molecular assembly, physical properties like thermal stability, dissolution and solubility may be correlated in a predictable manner with molecular structure. , $^{9,10}$

Previously, we demonstrated how a careful selection of cocrystallizing agents, provide structural control leading to either 1-

${ }_{45} \mathrm{D}$ networks or 0-D assemblies, focusing mainly on the primary synthons with less emphasis on weaker interactions. ${ }^{11}$

In our current study, we highlight how weaker secondary interactions influence the organization of 1-D motifs into assemblies of higher dimensionality, as well as on possible 50 connections between structural consistency and reliable structureproperty correlation. For this purpose we choose two isomeric azopyridine systems, i.e. 4,4'-azopyridine (4,4'-azpy) and 3,3'azopyridine (3,3'-azpy) and a series of aliphatic even-chain dicarboxylic acids; succinic, adipic, suberic and sebacic acid 55 (increasing number of carbon atoms in their aliphatic backbone). The two azo-pyridines differ in the relative orientation of their hydrogen-bond acceptor sites; in 4,4'-azpy the binding sites are almost co-linear whereas in the case of 3,3'-azpy they are parallel (Scheme 1).
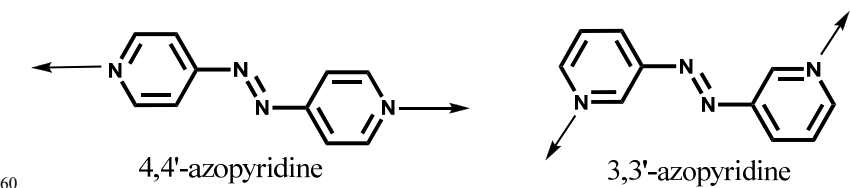

3,3'-azopyridine

Scheme 1

The main driving force in the co-crystal assembly is expected to be the acid-pyridine, i.e. $\mathrm{COOH} \cdots \mathrm{N}$ (py) heterosynthon (Scheme ${ }_{65} 2$ ), which has many precedents in literature. ${ }^{12}$ Increasing the number of carbon atoms in the acid co-former should not affect this key interaction; however, the enhanced hydrophobicity and spacing of carboxylic acid moieties, could certainly influence the secondary interactions. Some co-crystals of 4,4'-azpy have been 70 previously reported ${ }^{13,14}$ but we now add an additional example as well as report the structures of four new 3,3'-azpy co-crystals in order to systematically elucidate the role of weaker forces on supramolecular assembly. In addition, we also seek to discover if it is possible to relate thermal behaviour of the co-crystals to any 
characteristics of the individual molecules or to any systematic structural patterns that may appear in these families of compounds.<smiles></smiles>

Scheme 2 Acid-pyridine heterosynthon
1) Can we achieve structural consistency in these two groups of azopyridine co-crystals of aliphatic diacids?

10 2) Can we then identify any correlations between molecular structure, crystal structure and physical properties?

3) What effect does the position of the hydrogen-bond acceptor sites have on packing pattern and physical property?

${ }_{15}$ We have postulated four different motifs that could be prepared by combining 3,3'-azpy and 4,4'-azpy with even-chain aliphatic diacids. The basic assumption is that chains will form in all cases, and they could then be arranged either out-of-phase (motifs 1 and 3 ) or in-phase (motif 2 and 4) within a 2-D architecture 20 constructed via inter-chain interactions, (Scheme 3 ).

In brief, we propose to answer the following questions;

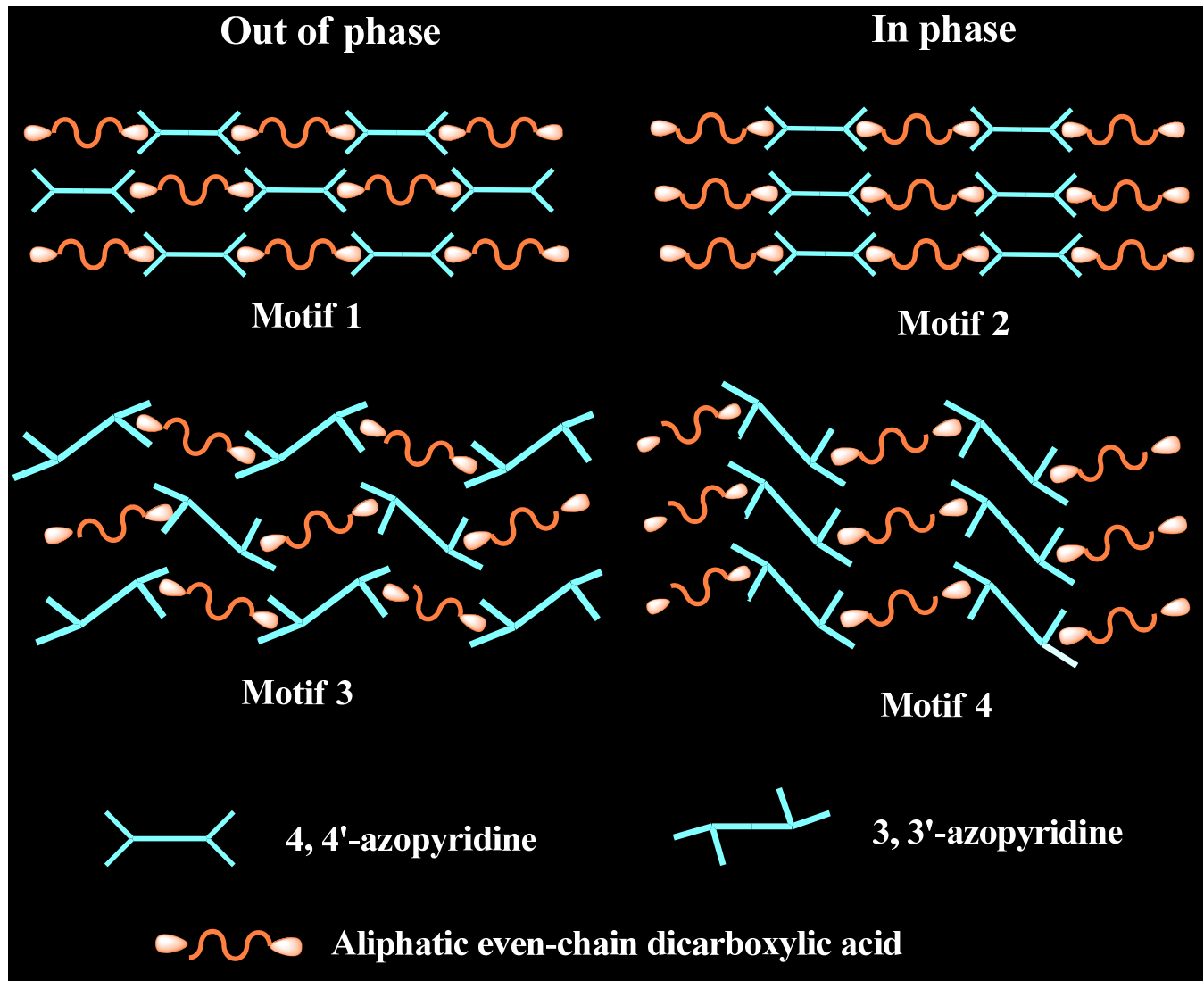

Scheme 3. Postulated motifs for the combination of 3,3'- and 4,4'-azopyridine with aliphatic diacids.

\section{${ }_{30}$ Experimental Section}

All precursors for the synthesis of 3,3'- and 4,4'-azopyridine were purchased from Aldrich and used without further purification. Melting points were determined using Fischer-Johns ${ }_{35}$ Mel-Temp melting point apparatus and uncorrected. ${ }^{1} \mathrm{H}$ NMR spectra were recorded on Varian $400 \mathrm{MHz}$ and $200 \mathrm{MHz}$ spectrometer. IR spectra of compounds and co-crystals were taken on a Nicolet 380 FT-IR. 


\section{Synthesis of 3,3'- and 4,4'-azopyridine}

\section{3,3'-azopyridine}

The synthesis of 3,3'-azpy was carried out using a previously 5 reported procedure. ${ }^{15} \mathrm{KOH}(16.26 \mathrm{~g}, 0.4 \mathrm{~mol})$ was dissolved in $100 \mathrm{ml}$ of water and kept in an ice bath. Using a dropping funnel, bromine $(5.24 \mathrm{ml}, 0.1 \mathrm{~mol})$ was slowly added to the $\mathrm{KOH}$ solution with stirring, maintaining the temperature between $0-5{ }^{\circ} \mathrm{C}$. After the addition was complete, 3 -amino pyridine $(1.9 \mathrm{~g}, 0.02 \mathrm{~mol})$

10 dissolved in $40 \mathrm{ml}$ of cold water was slowly added to it. The resulting mixture was stirred in an ice-bath for $1-2 \mathrm{hrs}$. The solution was extracted into methylene chloride and the solvent was removed under reduced pressure. The resultant crude was subjected to column chromatography and the pure product was 15 isolated in $46 \%$ yield. Mp 132-134 ${ }^{\circ} \mathrm{C}$ (lit. 136-140 ${ }^{\circ} \mathrm{C}$ ); ${ }^{1} \mathrm{H}$ NMR $\left(\delta \mathrm{H}, 400 \mathrm{MHz}, \mathrm{CDCl}_{3}\right): 9.17(\mathrm{~d}, 2 \mathrm{H}), 8.79(\mathrm{~s}, 2 \mathrm{H}), 8.23(\mathrm{~d}, 2 \mathrm{H})$, $7.66(\mathrm{t}, 2 \mathrm{H})$.

4,4'-azopyridine:

${ }_{20}$ The synthesis of 4,4'-azpy was carried out using a slightly modified procedure. ${ }^{16}$ 4-Amino pyridine $(2.5 \mathrm{~g}, 0.025 \mathrm{~mol})$ was dissolved in $40 \mathrm{ml}$ water and kept cold in an ice bath. $6 \% \mathrm{NaOCl}$ $(50 \mathrm{ml}, 0.0036 \mathrm{~mol}$ diluted with $50 \mathrm{ml}$ water) was added drop wise to the pyridine solution with constant stirring while maintaining 25 the temperature between $0-5^{\circ} \mathrm{C}$. After stirring for 2-3 hrs in the ice-bath, the product was extracted into ether. After removing the solvent under reduced pressure, a small amount of hexane was added to the crude (to dissolve the product). Any insoluble residue was discarded. The solvent was then removed under 30 reduced pressure and pure bright-orange product was recrystallized from methanol in 51\% yield. Mp 106-109 ${ }^{\circ} \mathrm{C}$ (lit.105$\left.106{ }^{\circ} \mathrm{C}\right) ;{ }^{1} \mathrm{H}$ NMR $\left(\delta \mathrm{H}, 400 \mathrm{MHz}, \mathrm{CDCl}_{3}\right): 8.88(\mathrm{~d}, 4 \mathrm{H}), 7.76(\mathrm{~d}$, $4 \mathrm{H})$.

${ }_{35}$ Co-crystal of 3,3'- and 4,4'-azopyridine

3,3'-azpy and 4,4'-azpy were co-crystallized with four even-chain diacids (succinic, adipic, suberic and sebacic). Preliminary screening was carried out using solvent-assisted grinding after which the resulting solid was characterized using IR spectroscopy

40 to determine if a co-crystal had formed. A total of eight experiments were performed and in all eight cases, the IR spectrum showed prominent broad stretches near 1950 and 2450 $\mathrm{cm}^{-1}$ (Fig 1) indicative of intermolecular $\mathrm{O}-\mathrm{H} \cdots \mathrm{N}$ hydrogen bonds, thus confirming co-crystal formation (Table 1). Once the 45 appearance of co-crystals were confirmed by IR, slow evaporation experiments were set up using stoichiometric amounts of the acid and base in a suitable solvent at room temperature. Since structures of 4,4'-azpy with succinic, adipic and sebacic acid were previously reported, ${ }^{12,13}$ we analyzed the 50 remaining five compounds using single crystal X-ray diffraction.
Table 2 shows the summary of co-crystal synthesis.

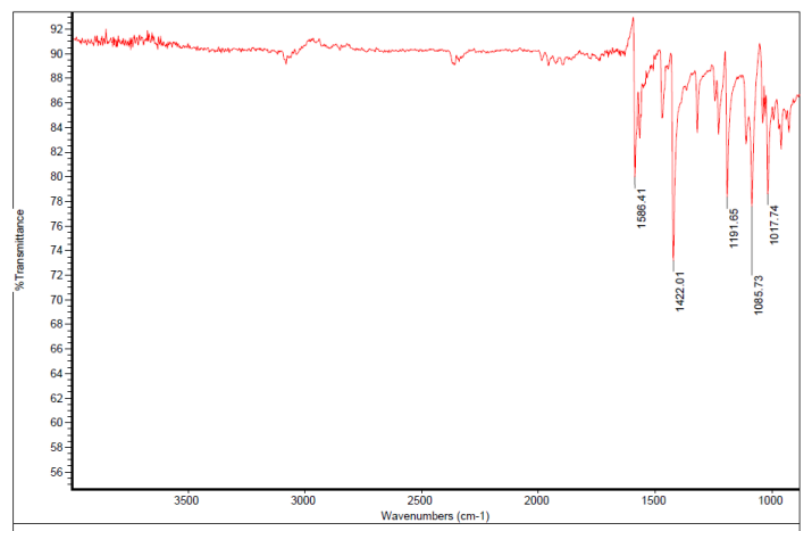

(a)

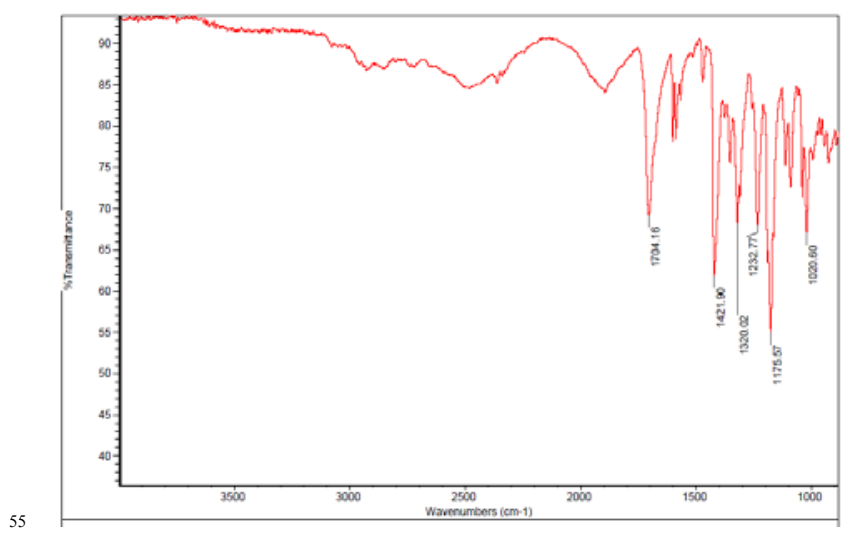

(b)

Fig.1 (a) IR spectrum of 3,3'-azpy; (b) IR of the product resulting from a combination of 3,3'-azpy and succinic acid (3,3'-azpy:SA) showing two 60 broad stretches near 1950 and $2450 \mathrm{~cm}^{-1}$ region.

Table 1. IR Carbonyl $\mathrm{C}=\mathrm{O}$ stretch and $\mathrm{O}-\mathrm{H} \cdots \mathrm{N}$ bands for co-crystals of 3,3' and 4,4'-azopyridine co-crystals

$\begin{array}{cccc}\text { Compound } & \begin{array}{c}\mathrm{O}-\mathrm{H} \cdots \mathrm{N} \text { stretches } \\ \left(\mathrm{cm}^{-1}\right)\end{array} & \begin{array}{c}\text { Co-crystal } \\ \mathrm{C}=\mathrm{O} \text { stretch } \\ \left(\mathrm{cm}^{-1}\right)\end{array} & \begin{array}{c}\text { Acid } \\ \mathrm{C}=\mathrm{O} \text { stretch } \\ \left(\mathrm{cm}^{-1}\right)\end{array} \\ \text { 3,3'-azpy-SA } & 2485 ; 1896 & 1702 & 1686 \\ \text { 3,3'-azpy-AA } & 2493 ; 1890 & 1691 & 1683 \\ \text { 3,3'-azpy-SuA } & 2471 ; 1881 & 1692 & 1684 \\ \text { 3,3'-azpy-SeA } & 2478 ; 1886 & 1693 & 1682 \\ \text { 4,4'-azpy-SuA } & 2484 ; 1883 & 1689 & 1684\end{array}$


Table 2. 3,3'and 4,4'-azopyridine co-crystal synthesis

\begin{tabular}{|c|c|c|c|c|c|}
\hline Azopyridine:acid & Abbreviation & Mole ratio & Solvent and method & Condition & $\begin{array}{l}\text { Melting point } \\
{ }_{\left({ }^{\circ} \mathrm{C}\right)}\end{array}$ \\
\hline $\begin{array}{l}\text { 3,3'-azopyridine: } \\
\text { succinic acid }\end{array}$ & 3,3'-azpy:SA & $1: 1$ & $\begin{array}{c}\text { Ethanol- slow } \\
\text { evaporation }\end{array}$ & $\begin{array}{l}\text { Ambient temp } \\
\text { for } 7 \text { days }\end{array}$ & $144-146$ \\
\hline $\begin{array}{c}\text { 3,3'-azopyridine: } \\
\text { adipic acid }\end{array}$ & 3,3'-azpy:AA & $1: 1$ & $\begin{array}{c}\text { Ethanol- slow } \\
\text { evaporation }\end{array}$ & $\begin{array}{l}\text { Ambient temp } \\
\text { for } 14 \text { days }\end{array}$ & $149-151$ \\
\hline $\begin{array}{c}\text { 3,3'-azopyridine: } \\
\text { suberic acid }\end{array}$ & 3,3'-azpy:SuA & $1: 1$ & Methanol-slow evaporation & $\begin{array}{l}\text { Ambient temp } \\
\text { for } 5 \text { days }\end{array}$ & $133-136$ \\
\hline $\begin{array}{c}\text { 3,3'-azopyridine: } \\
\text { sebacic acid }\end{array}$ & 3,3'-azpy:SeA & $1: 1$ & Methanol-slow evaporation & $\begin{array}{l}\text { Ambient temp } \\
\text { for } 9 \text { days }\end{array}$ & $122-125$ \\
\hline $\begin{array}{l}\text { 4,4'-azopyridine: } \\
\text { succinic acid }\end{array}$ & 4,4'-azpy:SA & $1: 1$ & Methanol-slow evaporation & $\begin{array}{l}\text { Ambient temp } \\
\text { for } 7 \text { days }\end{array}$ & $205-209$ \\
\hline $\begin{array}{c}\text { 4,4'-azopyridine: } \\
\text { adipic acid }\end{array}$ & 4,4'-azpy:AA & $1: 1$ & Methanol-slow evaporation & $\begin{array}{l}\text { Ambient temp } \\
\text { for } 28 \text { days }\end{array}$ & 189-192 \\
\hline $\begin{array}{c}\text { 4,4'-azopyridine: } \\
\text { suberic acid }\end{array}$ & 4,4'-azpy:SuA & $1: 1$ & Ethanol-slow evaporation & $\begin{array}{l}\text { Ambient temp } \\
\text { for } 25 \text { days }\end{array}$ & $160-163$ \\
\hline $\begin{array}{c}\text { 4,4'-azopyridine: } \\
\text { sebacic acid }\end{array}$ & 4,4'-azpy:SeA & $1: 1$ & Methanol-slow evaporation & $\begin{array}{l}\text { Ambient temp } \\
\text { for } 12 \text { days }\end{array}$ & $144-147$ \\
\hline
\end{tabular}

\section{X-Ray crystallography}

With the exception of 3,3'-azpy:SA, whose dataset was collected on a Bruker-AXS SMART APEXII diffractometer, datasets were collected on Bruker-AXS Kappa APEX II equipment. All datasets were collected at $120 \mathrm{~K}$ using APEX2 software. An ${ }_{10}$ Oxford Cryostream 700 low-temperature device was used to control temperature. MoK $\alpha$ radiation was used. Initial cell constants were found by small widely separated "matrix" runs. Data collection strategies were determined using COSMO. Scan speeds and scan widths were chosen based on scattering power 15 and peak rocking curves.

Unit cell constants and orientation matrices were improved by least-squares refinement of reflections threshold from the entire dataset. Integrations were performed with SAINT, using these improved unit cells as a starting point. Precise unit cell constants 20 were calculated in SAINT from the final merged datasets. Lorenz and polarization corrections were applied. Absorption corrections were applied for all datasets.

Datasets were reduced with SHELXTL. The structures were solved by direct methods without incident. All structures were 25 completely ordered, and no disordering models were required. All materials crystallized with 1:1 azopyridine: diacid stoichiometry. With the exception of the carboxylic acid hydrogen atoms, whose coordinates were allowed to refine, all hydrogens were assigned to idealized positions and were allowed to ride. With the 30 exception of 3,3'-azpy:SeA, for which the diamine / diacid pair sits on a general position, all structures show crystallographic inversion symmetry for both the diamine and the diacid. Isotropic thermal parameters for the hydrogen atoms were constrained to be $1.5 \mathrm{x}$ (methyl) / 1.2x (all other) that of the connected atom.

${ }_{35}$ Selected hydrogen bond geometries are shown in Table 3 and crystallographic parameters of 3,3'- and 4,4'-azpy co-crystals are listed in Table 4.

Table 3. Hydrogen bond geometries in co-crystals of 3,3'and 4,4'-azopyridine

\begin{tabular}{|c|c|c|c|c|c|}
\hline Structure & D-H $\cdots \mathbf{A} / \mathbf{A}$ & D-H/Å & H...A/Å & $\mathbf{D} \cdots \mathbf{A} / \AA$ & D-H $\cdots N{ }^{0}$ \\
\hline 3,3'-azpy:SA & $\mathrm{O}(21)-\mathrm{H}(21) \ldots \mathrm{N}(11)$ & $0.946(15)$ & $1.748(15)$ & $2.6924(12)$ & $176.5(13)$ \\
\hline 3,3'azp:AA & $\mathrm{O}(21)-\mathrm{H}(21) \ldots \mathrm{N}(11)$ & $0.913(17)$ & $1.778(17)$ & $2.6893(11)$ & $176.5(15)$ \\
\hline 3,3'-azpy:SuA & $\mathrm{O}(21)-\mathrm{H}(21) \ldots \mathrm{N}(11)$ & $0.925(16)$ & $1.756(16)$ & $2.6798(11)$ & $177.0(13)$ \\
\hline \multirow[t]{2}{*}{ 3,3'-azpy:SeA } & $\mathrm{O}(31)-\mathrm{H}(31) \ldots \mathrm{N}(11)$ & $1.04(3)$ & $1.65(3)$ & $2.682(3)$ & $175(2)$ \\
\hline & $\mathrm{O}(40)-\mathrm{H}(40) \ldots \mathrm{N}(21) \_\# 1$ & $1.08(3)$ & $1.61(3)$ & $2.683(3)$ & $171(2)$ \\
\hline 4,4'-azpy:SuA & $\mathrm{O}(21)-\mathrm{H}(21) \ldots \mathrm{N}(11)$ & $0.885(17)$ & $1.809(18)$ & $2.6633(13)$ & $161.6(15)$ \\
\hline
\end{tabular}

40 Symmetry codes: $\# 11+x, 1+y, 1+z$ 
Cite this: DOI: 10.1039/coxxooooox

www.rsc.org/xxxxxx

ARTICLE TYPE

Table 4. Crystallographic parameters of 3,3' and 4,4'-azopyridine co-crystals

\begin{tabular}{|c|c|c|c|c|c|}
\hline Formula moiety & $\begin{array}{c}\text { 3,3'-azpy:SA } \\
\left(\mathrm{C}_{10} \mathrm{H}_{8} \mathrm{~N}_{4}\right) \\
\left(\mathrm{C}_{4} \mathrm{H}_{6} \mathrm{O}_{4}\right)\end{array}$ & $\begin{array}{c}\text { 3,3'-azpy:AA } \\
\left(\mathrm{C}_{10} \mathrm{H}_{8} \mathrm{~N}_{4}\right) \\
\left(\mathrm{C}_{6} \mathrm{H}_{10} \mathrm{O}_{4}\right)\end{array}$ & $\begin{array}{c}\text { 3,3'-azpy:SuA } \\
\left(\mathrm{C}_{10} \mathrm{H}_{8} \mathrm{~N}_{4}\right) \\
\left(\mathrm{C}_{8} \mathrm{H}_{14} \mathrm{O}_{4}\right)\end{array}$ & $\begin{array}{c}\text { 3,3'-azpy:SeA } \\
\left(\mathrm{C}_{10} \mathrm{H}_{8} \mathrm{~N}_{4}\right) \\
\left(\mathrm{C}_{10} \mathrm{H}_{18} \mathrm{O}_{4}\right)\end{array}$ & $\begin{array}{c}\text { 4,4'-azpy:SuA } \\
\left(\mathrm{C}_{10} \mathrm{H}_{8} \mathrm{~N}_{4}\right) \\
\left(\mathrm{C}_{8} \mathrm{H}_{14} \mathrm{O}_{4}\right)\end{array}$ \\
\hline Empirical formula & $\mathrm{C}_{14} \mathrm{H}_{14} \mathrm{~N}_{4} \mathrm{O}_{4}$ & $\mathrm{C}_{16} \mathrm{H}_{18} \mathrm{~N}_{4} \mathrm{O}_{4}$ & $\mathrm{C}_{18} \mathrm{H}_{22} \mathrm{~N}_{4} \mathrm{O}_{4}$ & $\mathrm{C}_{20} \mathrm{H}_{26} \mathrm{~N}_{4} \mathrm{O}_{4}$ & $\mathrm{C}_{18} \mathrm{H}_{22} \mathrm{~N}_{4} \mathrm{O}_{4}$ \\
\hline Molecular weight & 302.29 & 330.34 & 358.40 & 386.45 & 358.40 \\
\hline Color, Habit & orange plate & orange prism & orange plate & orange plate & orange prism \\
\hline Crystal system & Monoclinic & Triclinic & Triclinic & Triclinic & Triclinic \\
\hline Space group, $\mathrm{Z}$ & $\mathrm{P} 21 / \mathrm{c}, 2$ & P-1, 1 & P-1, 1 & P-1, 2 & P-1, 1 \\
\hline $\mathrm{a}, \AA$ & $11.9092(7)$ & $5.2025(4)$ & $5.4680(6)$ & $7.0388(14)$ & $5.8269(6)$ \\
\hline $\mathrm{b}, \AA$ & $5.2342(3)$ & 7.0703(6) & 7.0381(7) & $8.2451(18)$ & $8.6817(8)$ \\
\hline $\mathrm{c}, \AA$ & $11.3589(7)$ & $11.4579(10)$ & $11.9358(12)$ & $17.490(4)$ & $9.0827(9)$ \\
\hline$\alpha,{ }^{\circ}$ & 90.00 & $99.247(5)$ & $98.867(6)$ & $77.525(14)$ & $76.314(6)$ \\
\hline$\beta, \circ$ & $91.198(3)$ & $102.957(6)$ & $93.592(6)$ & $80.368(13)$ & $87.963(6)$ \\
\hline$\gamma,^{\circ}$ & 90.00 & $101.395(5)$ & $102.392(6)$ & $85.474(14)$ & $77.486(6)$ \\
\hline $\mathrm{V}, \AA^{3}$ & $707.90(7)$ & $393.25(6)$ & $441.09(8)$ & $976.1(3)$ & $435.76(7)$ \\
\hline Instrument & SMART APEX II & Kappa APEX II & Kappa APEX II & Kappa APEX II & Kappa APEX II \\
\hline Density, $\mathrm{g} / \mathrm{cm}^{3}$ & 1.418 & 1.395 & 1.349 & 1.315 & 1.366 \\
\hline Temperature, $\mathrm{K}$ & $120(2)$ & $120(2)$ & $120(2)$ & $120(2)$ & $120(2)$ \\
\hline $\mathrm{MoK}_{\alpha}, \AA$ & 0.71073 & 0.71073 & 0.71073 & 0.71073 & 0.71073 \\
\hline$\mu, \mathrm{mm}^{-1}$ & 0.107 & 0.103 & 0.097 & 0.093 & 0.098 \\
\hline$\theta_{\min }, \circ$ & 1.71 & 1.87 & 1.74 & 2.41 & 2.31 \\
\hline$\theta_{\max }, \circ$ & 31.49 & 32.40 & 32.03 & 31.00 & 33.12 \\
\hline Absorption correction & multi-scan & multi-scan & multi-scan & multi-scan & multi-scan \\
\hline trans $\min / \max$ & 0.9626 / 0.9936 & $0.9758 / 0.9858$ & $0.9770 / 0.9923$ & $0.9780 / 0.9944$ & $0.9748 / 0.9863$ \\
\hline Reflections & & & & & \\
\hline collected & 8074 & 9100 & 10333 & 6041 & 9736 \\
\hline independent & 2256 & 2738 & 3043 & 6041 & 3144 \\
\hline observed & 1785 & 2187 & 2427 & 2977 & 2201 \\
\hline Threshold expression & $>2 \sigma(\mathrm{I})$ & $>2 \sigma(\mathrm{I})$ & $>2 \sigma(\mathrm{I})$ & $>2 \sigma(\mathrm{I})$ & $>2 \sigma(\mathrm{I})$ \\
\hline $\mathrm{R}_{1}$ (observed) & 0.0406 & 0.0489 & 0.0476 & 0.0930 & 0.0504 \\
\hline$w \mathrm{R}_{2}($ all $)$ & 0.1181 & 0.1451 & 0.1484 & 0.2462 & 0.1459 \\
\hline $\mathrm{S}$ & 1.131 & 1.036 & 1.087 & 1.177 & 1.075 \\
\hline
\end{tabular}

\section{${ }_{5}$ Results}

We have reported five co-crystals of azopyridine with dicarboxylic acids; 3,3'-azpy:SA, 3,3'-azpy:AA, 3,3'-azpy:SuA, 3,3'-azpy:SeA and 4,4'-azpy:SuA. All of them appear in a 1:1

10 stoichiometry, four of them crystallize in the triclinic $P-1$ space group, whereas 3,3'-azpy:SA crystallizes in the monoclinic space group $P 2{ }_{1} / c$.

${ }_{15}$ Crystal structures of 3,3'-azpy:AA, 3,3'-azpy:SuA, and 3,3'azpy:SeA.

All these three co-crystals show the expected $\mathrm{O}-\mathrm{H} \cdots \mathrm{N}$ intermolecular hydrogen bonds between carboxylic acid and azopyridine, resulting in infinite 1-D zig-zag tapes. The 1-D 20 tapes are organized into two-dimensional planar sheets via auxiliary intermolecular $\mathrm{C}-\mathrm{H} \cdots \mathrm{O}$ interactions and close contacts between azopyridine molecules. All three structures show similar interactions and arrangements in both dimensions (Figure 2a-c) resembling an in-phase packing (motif 4 , scheme 3 ). 


\section{Journal Name}

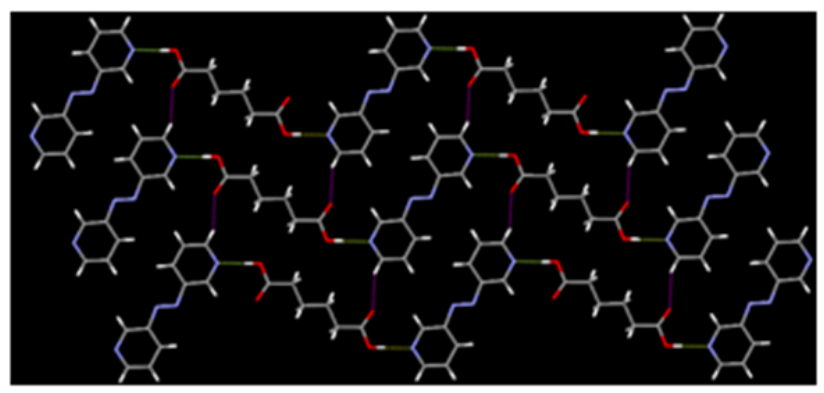

a

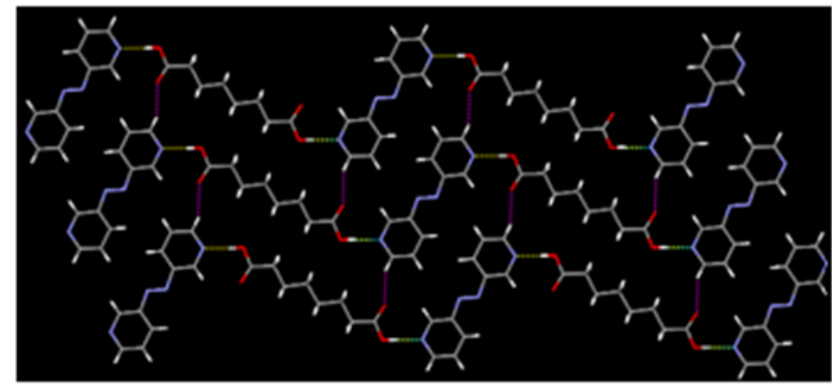

b

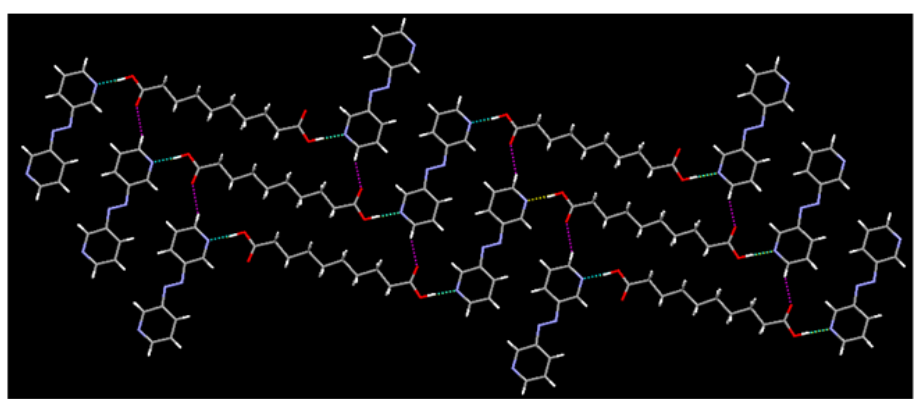

C

Fig. 2 The arrangement of 1-D chains into 2-D planar sheet via inter-chain C-H ‥ O hydrogen bonds in the crystal structures of a) 3,3'azpy:AA, b) 3,3'-azpy:SuA and c) 3,3'-azpy:SeA.

\section{- Crystal structure of 3,3'-azpy:SA}

The crystal structure of 3,3'-azpy:SA displays an unexpected motif as a result of different weaker interactions (Fig 3). The primary interaction is consistent with the three earlier compounds, i.e. a acid $\cdots$ pyridine heterosynthons, which produce 10 1-D zig-zag chains. The chains are further organized into a 2-D network via acid molecules aligned perpendicular to the plane, which is different to the previously observed motif 4 in the structures of 3,3'-azpy:AA, 3,3'-azpy:SuA and 3,3'-azpy:SeA.

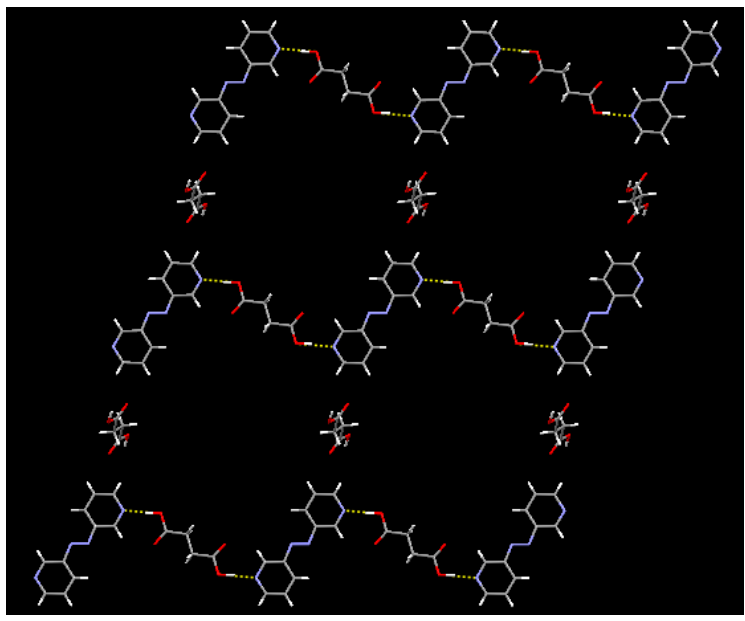

Fig. 3 In the crystal structure of 3,3'-azpy:SA there are 1-D zig-zag chains interconnected via acid molecules perpendicular to the chains. 
Crystal structure of 4,4'-azpy:SuA

In contrast to the crystal structures for acid co-crystals of 3,3'5 azpy, 4,4'-azpy:SuA exhibits motif 1 (Scheme 3). The O-H $\cdots \mathrm{N}$ primary interactions lead to infinite 1-D chains that are further organized into a 2-D layer via secondary $\mathrm{C}-\mathrm{H} \cdots \mathrm{O}$ interactions (Fig.4).

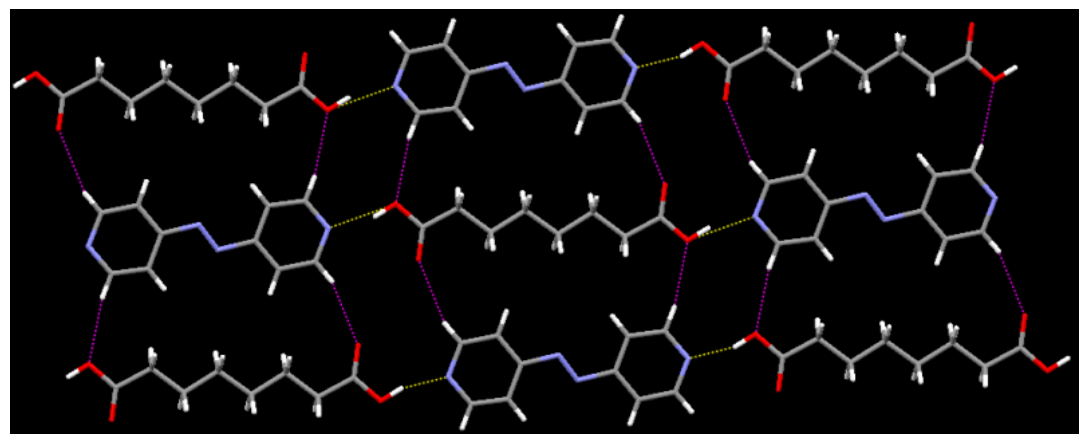

Fig.4 2-D planar sheet formed by infinite 1-D chains arranged in the crystal structure of 4,4'-azpy:SuA

\section{Discussion}

Based on our experimental results (Table 1) azopyridines are very 15 effective at forming co-crystals with aliphatic diacids (5/5 attempts, and in no case was proton transfer observed). The synthetic success can be attributed to the robust pyridine-acid heterosynthon, i.e. $\mathrm{COOH} \cdots \mathrm{N}(\mathrm{py})$. This synthon is present in all these crystal structures, while the secondary interactions, (py)C${ }_{20} \mathrm{H} \cdots \mathrm{O}$ (acid) hydrogen bonds, help to produce a limited variety of 2-D motifs.

\section{Structural behavior of azopyridine:diacid co-crystals}

3,3'-azopyridine co-crystals

${ }_{25}$ Motif 4 (Scheme 3) is the most common feature in 3,3'azpy:diacid crystal structures. The primary interaction, i.e. the acid-pyridine hetero-synthon, produces infinite 1-D corrugated chains which are then combined into 2-D planar sheets via

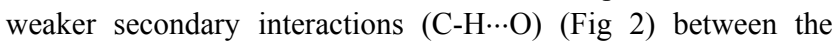
30 carbonyl oxygen and a pyridyl $\mathrm{C}-\mathrm{H}$ site of a neighbouring chain (as found in 3,3'-azpy:AA, 3,3'-azpy:SuA and 3,3'-azpy:SeA) 3,3'-azpy:SA, however lacks a similarly close-packed structure Fig 3, which is also reflected in its melting point, as noted below.

\section{${ }_{35}$ 4,4'-azopyridine co-crystals}

We have added the crystal structure of 4,4'-azpy:suberic acid, to the previously reported co-crystals with succinic, adipic and sebacic acid (Fig 4 and 5a-c). ${ }^{13,14}$ An examination of all structures shows that motif 1 is present three times (4,4'-azpy:AA, 4,4'40 azpy-SA, and 4,4'-azpy:SuA) and motif 2 is present once (4,4'azpy:SeA), (Scheme 3, Fig 4 and 5a-c). Motif 2 is corrugated in contrast to the planarity of motif 1 .

For comparison, $\mathrm{Wu}$ and co-workers ${ }^{13,14}$ synthesised a series of co-crystals of geometrically related targets, 4,4'ethylene bipyridyl ${ }_{45}$ (BPE) and 4,4'-azopyridine with aliphatic dicarboxylic acids, to establish a binding pattern as a function of the size of two components in the crystal lattice. When the two components are of comparable size, motif 1 is preferred as shown by BPE:adipic acid, BPE:succinic acid, 4,4'-azpy:adipic acid, and 4,4'50 azpy:succinic acid. These results are consistent with what we found for 4,4'-azopy:suberic acid which exhibits motif 1 . A similar motif is also observed in the 4,4'bipyridyl co-crystal with adipic acid. ${ }^{17}$ However, if the two components that make up the co-crystal have a noticeable size mis-match, then it seems that 55 motif 2 is preferred, as shown in 4,4'-azpy:sebacic acid and bipy:sebacic acid. ${ }^{17}$

A similar behaviour is noted for the 3,3'-azopyridine system. All co-crystals with a layered architecture, regardless of the acid chain length, gave motif 4 . This is likely because the two binding ${ }_{60}$ sites are no longer co-linear (as was the case in 4,4'-azpy) and they naturally orient themselves to form corrugated chains. However, succinic acid, the shortest diacid examined in this study (and the one with the largest size mis-match with respect to the length of 3,3'-azpy), cannot sustain a close-packed layered 65 arrangement, and breaks with the common appearance.

In brief, an examination of all eight crystal structures of 3,3'-and 4,4'-azopyridine show the following distribution of observed motifs (Table 5). 


\section{Journal Name}

\section{Cite this: DOI: 10.1039/coxxo0000x}

Table 5 Summary of different motifs seen in crystal structures

\begin{tabular}{|c|c|c|c|c|c|}
\hline & Motif 1 & Motif 2 & Motif 3 & Motif 4 & $\begin{array}{l}\text { Unexpected } \\
\text { motif }\end{array}$ \\
\hline $\begin{array}{l}\text { 3,3'-azpy } \\
\text { co-crystals }\end{array}$ & - & - & - & $3 / 4$ & $1 / 4$ \\
\hline $\begin{array}{c}\text { 4,4'-azpy } \\
\text { co-crystals }\end{array}$ & $3 / 4$ & $1 / 4$ & - & - & - \\
\hline
\end{tabular}

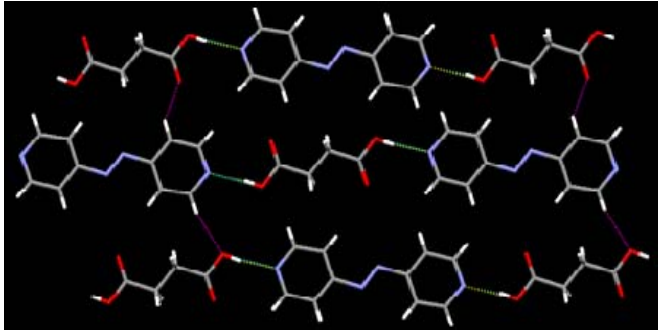

a

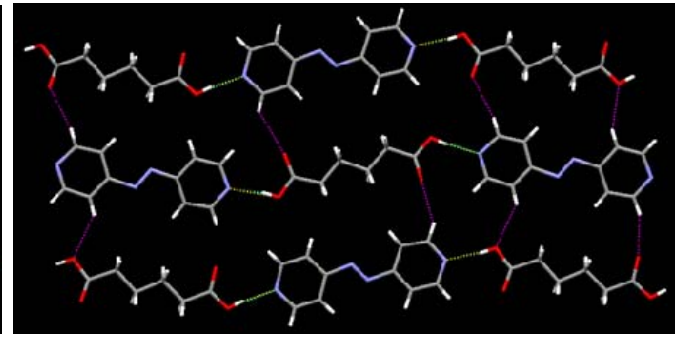

b

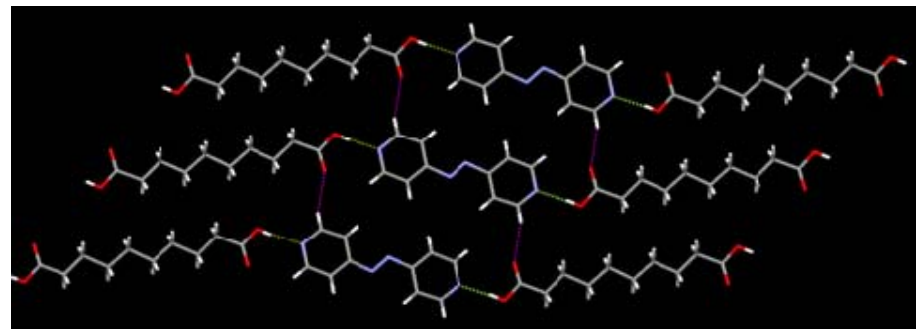

C

Fig. 5 2-D planar sheets in crystal structures of 4,4'-azpy:SA (5a), 4,4'-azpy:AA (5b) and 4,4'-azpy:SeA (5c) ${ }^{13}$

\section{Thermal behaviour of azopyridine:diacid co-crystals}

The melting point of any solid is a fundamental physical property that may also have important implications for a range of applications, as well as for processing and shelf-life. If molecular structure and thermal behaviour can be interrelated, then we can

15 modulate the physical properties of a library of compounds using simple co-crystallization techniques.
Based on our results, the thermal behaviour of azopyridine cocrystals can be correlated to molecular structure;

1) As a function of acid chain length and its melting point within 20 individual groups (Fig 6).

2) As a function of binding site geometrical bias in 3,3'-and 4,4'azopyridine co-crystals (Fig 6). 


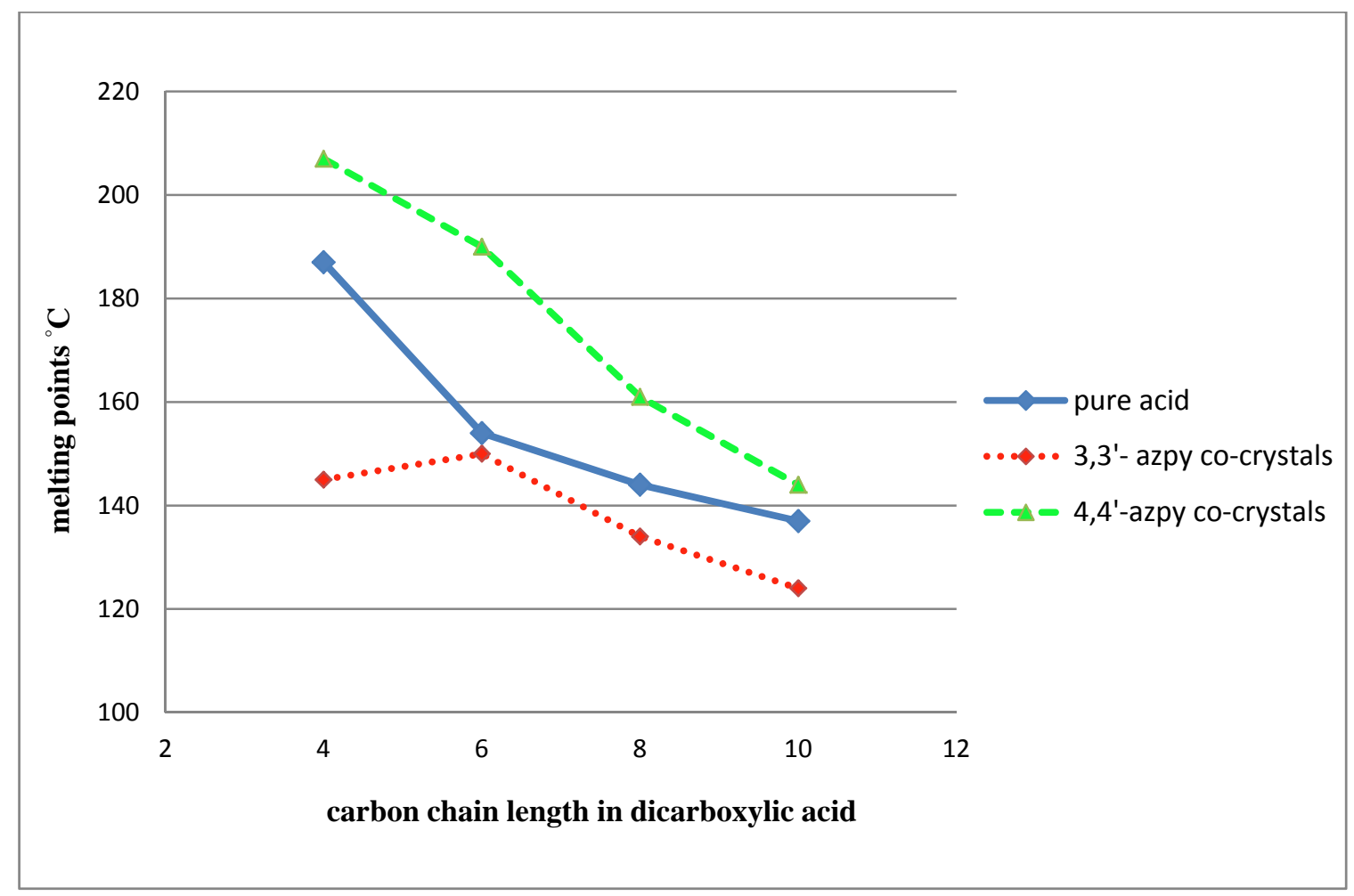

Fig 6. Melting point correlation between co-crystals of 3,3'-and 4,4'-azopyridine and molecular structure of the acid.

In co-crystals of 4,4'-azpy with succinic, adipic, suberic and sebacic acid (Fig 4 and 5a-c), structural consistency is maintained 10 as we systematically increase the length of the diacid. Consequently, co-crystal melting points show a near-linear correlation with the carbon chain length in the corresponding diacids, which indicates a strong and predictable structureproperty interdependence. The melting points of the pure diacids 15 also decrease upon moving from shorter to longer chain acids. The same trend is also maintained in their co-crystals with 4,4'azopyridine. Despite the fact that 4,4'-azpy:SeA exhibits motif 2, instead of motif 1 (observed in all other cases), its melting behaviour does not show significant difference from this pattern.

20 This underlines the importance of the weaker intra-layer interactions that hold adjacent layers in close proximity.

3,3'-azpy co-crystals also show melting point decreases concomitant with an increase in the diacid carbon chain length (Fig 6). The only outlier is 3,3'-azpy:SA, with a lower melting 25 point than expected. This incongruity can be explained based on its crystal structure (Fig 3) which shows a very different packing arrangement compared to that of the others (Fig 2a-c). The corrugated layers in 3,3'-azpy:SA are not closely packed, and instead separated by acid molecules aligned perpendicular to the

30 plane of the sheet. This unusual behaviour is possibly due to the shorter length of the diacids, which makes close packing of layers less favourable.

Based on the results of thermal behavior-structural analysis of the two classes of co-crystals, a reliable connection between physical
35 properties of individual molecules and their multi-component systems can be made as long as structural consistency is maintained. Any deviation from this can lead to dramatic alterations in the overall physical properties of the bulk, as seen in the case of 3,3'-azpy:SA.

40 The position of the primary binding site in supramolecular target plays an important role in the molecular arrangement of building blocks. Alterations in the relative position on the molecular backbone changes its relative orientation within a solid framework, which affects the overall assembly process and thus 45 the physical properties of the solid. In our system, 3,3' and 4,4'azopyridine differ in the relative position of their pyridine acceptor sites, (Scheme 1). Although this geometrical bias does not impact the binding preference with diacids, (i.e. the acidpyridine heterosynthon) the packing pattern shows a significant 50 deviation.

The co-crystals of two azopyridine targets show very different melting points with same diacids (Fig 6). 3,3'-azpy co-crystals have lower melting points than the corresponding 4,4'-azpy cocrystals (despite the fact that 3,3-azpy itself has a higher melting ${ }_{55}$ point than pure 4,4 '-azpy). In order to try to find a possible explanation for the observed melting points, we compared the densities for the two classes of co-crystals but they were, in fact, very similar. We also closely examined any possible differences in the presence of weaker intra- or interlayer interactions but, 60 again, no obvious differences presented themselves. It seems that more structural data is needed in order to find a plausible 
explanation for these differences.

Based on the analysis of crystal structures and corresponding 5 melting points of 3,3'- and 4,4'-azpy co-crystals, we can conclude that these two bipy-related compounds are very efficient at forming co-crystals with aliphatic dicarboxylic acids. Furthermore, if structural control can be maintained within a series of related co-crystals, it is possible to estimate the how 10 physical properties may trend or even their relative magnitude purely based on the molecular structure of one of the two components. Finally, the relative positions of binding sites on related compounds can also be used to prepare new solid-forms that display physical properties that can be fine-tuned with 15 respect to those of the individual components.

\section{Acknowledgments}

We are grateful for financial support from the NSF (CHE0957607).

${ }^{a}$ Department of Chemistry, Kansas State University, 213 CBC building, Manhattan, KS 66506, United States.

E-mail: aakeroy@ksu.edu.

1 Making Crystals by Design-from Molecules to Molecular Materials, Methods, Techniques, Applications; F. Grepioni, D. Braga, Eds.;Wiley-VCH: Weinheim, Germany, 2007; pp209-240; J.D. Dunitz, A. Gavezzotti, Angew Chem., Int. Ed. 2005, 44, 1766-1787.

2 C.B. Aakeröy and D. J. Salmon, CrystEngComm, 2005, 7, 439; M. Wenger and J. Bernstein, Angew. Chem., Intl. Ed. 2006, 45, 79667969; J-M. Lehn, Science, 2002, 295, 2400; G. R. Desiraju, Acc. Chem. Res., 2002, 35, 565-573.

3 P. Metrangolo, T. Pillati, G. Resnati, A. Stevenazzi, Chem Commun, 2004, 1492-1493; P. Metrangolo, T. Pilati and G. Resnati, CrystEngComm, 2006, 8, 946-947; K. Raatikainen and K. Rissanen, CrystEngComm, 2011, 13, 6972-6977.

4 N. Boorah, R. J. Sarma and J.B. Baruah, CrystEngComm, 2006, 8, 608.

5 A. D. Bond, RSC Drug Discovery Series 1, 2012, 16, 9-28; G.R. Desiraju, CrystEngComm 2003, 5, 466-467; J. D. Dunitz, CrystEngComm, 2003, 5, 506.

6 A. V. Trask, W.D. Sam Motherwell, W. Jones, International Journal of Pharmaceutics, 2006, 320, 114-123; A. J. Smith, P. Kavuru, L. Wojtas, M. J. Zaworotko, D. R. Shytle, Mol. Pharmaceutics, 2011, 8, 1867-1876; N. Rodriguez-Hornedo, Molecular Pharmaceutics, 2007, 4, 299-300; A. V. Trask, Mol. Pharmaceutics, 2007, 4, 301-309.

7 K. B. Landenberger; A. J. Matzger, Cryst. Growth Des 2012, 12, 3603-3609.

8 C. B. Aakeröy, D. J. Salmon, M.M. Smith, J. Desper, Cryst. Growth Des, 2006, 4, 1033-1042; P. Vishweshwar, J. A. McMahon, M. L. Peterson, M. B. Hickey, T. R. Shattock, M. J. Zawarotko, ChemCommun, 2005, 36, 4601-4603; C. B. Aakeröy, A. M. Beatty, K. Lorimer, Molecular crystal and liquid crystals, 2006, 1, 163-174.

9 C. B. Aakeröy, S. Forbes and J. Desper, J. Am. Chem. Soc., 2009, 131, 17048-17049.

10 D. Braga, E. Dichiarante, G. Palladino, F. Grepioni, M R. Chierotti, R. Gobetto and L. Pellegrino, CrystEngComm, 2010, 12, 3534-3536.
11 C. B. Aakeröy, S. V. Panikkattu, B. DeHaven, and J. Desper Cryst. Growth Des, 2012, 12, 2579-2587.

12 T. R. Shattock, K. K. Arora, P. Vishweshwar, and M. J. Zaworotko, Cryst. Growth Des, 2008, 8, 4533-4545; C. B. Aakeröy, I. Hussain, S. Forbes and J. Desper, CrystEnggComm, 2007, 9, 46-54; B. R. Bhogala, A. Nangia, Cryst. Growth Des. 2003, 3, 547-554.

13 J. Zhang, L. Wu, Y. Fan, J. Mol. Structur., 2003, 660, 119-129.

14 J. Zhang, L. Ye, L. Wu, Acta Crystallogr.Section C, 2005, 61, 38-40.

15 G. P. Spaleniak, Z. Daszkiewicz, and J.B. Kyzio, Chemical papers, 2009, 3, 312-322.

16 N. Iranpoor, H. Firouzabadi, D. Khalili and S. Motevalli, J. Org. Chem. 2008, 73, 4882-4887.

17 V. R. Pedireddi, S. Chatterjee, A. Ranganathan, C.N.R. Rao, Tetrahedron, 1998, 54, 9457-9474. 